УДК 338

\title{
СТРАТЕГИЯ РАЗВИТИЯ ЧАСТНОГО \\ РЕАБИЛИТАЦИОННОГО ЦЕНТРА ДЛЯ ДЕТЕЙ \\ С НАРУШЕНИЯМИ РАЗВИТИЯ
}

\begin{abstract}
Федорова Юлия Павловна
бизнес-консультант и маркетолог в сфере образования основатель онлайн-школы руководителей образовательных проектов JPFedorova
\end{abstract}

Аннотация. В статье описана трехмесячная работа Юлии Федоровой с руководителем реабилитационного центра для детей с нарушениями развития. Пошагово изложены все составляющие стратегии, которая позволила центру укрепить свое положение на рынке и выйти на прибыльность в проекте. Статья будет полезна руководителям логопедических и реабилитационных центров, логопедам и дефектологам, работающим на рынке частного детского образования.

Ключевые слова: стратегия развития, маркетинг-план, позиционирование, бизнес-модель, анализ целевой аудитории, управление центром.

\section{THE CASE: DEVELOPMENT STRATEGY FOR A PRIVATE REHABILITATION CENTER FOR CHILDREN WITH DEVELOPMENTAL DISABILITIES}

\section{Fedorova Iuliia Pavlovna}

\begin{abstract}
The paper summarizes the three-month work performed by Iuliia Fedorova together with the head of a rehabilitation center for children with developmental disabilities. All the components of the strategy, which allowed the center to strengthen its position in the market and reach profitability in the project, are outlined step by step. The paper will be useful to the heads of speech therapy and rehabilitation centers, speech therapists and defectologists working in the market for private children's education.
\end{abstract}

Key words: development strategy, marketing plan, positioning, business model, target audience analysis, center management. 


\section{МОДЕРНИЗАЦИЯ СОВРЕМЕННОГО ОБРАЗОВАНИЯ: АНАЛИЗ ОПЫТА И ТЕНДЕНЦИЙ}

Начало работы с реабилитационным центром: февраль 2021 г.

Окончание работы: апрель 2021 г.

Исходная точка проекта:

- Реабилитационный центр для детей с нарушениями развития в одном из городов России с населением 400 тыс. жителей

- 7 сотрудников центра: логопеды, дефектологи, нейропсихолог, АВА-терапевт, руководитель

- Выручка проекта в месяц: 450 тыс. руб.

- Чистая прибыль в месяц: 0 руб.

- Количество одновременно обучающихся учеников центра: 30 детей

- Основные проблемы, с которыми пришел руководитель:

- не выстроено управление центром

- выручка едва покрывает расходы

- центр новый, проигрывает более известным конкурентам, которые работают в городе более 5 лет

- Сильные стороны проекта:

- высокая экспертиза руководителя и основателя центра

- команда высококлассных специалистов

- эффективные, зарекомендовавшие себя методики

- работа с самыми сложными случаями

Стратегию развития реабилитационного центра мы изначально строили, отталкиваясь от сильного конкурентного преимущества: специалисты центра не боялись браться за самые сложные случаи (диагнозы РАС, Синдром Дауна, ДЦП, ЗПРР) и умели добиваться улучшения ситуации.

Первый шаг создания стратегии развития и продвижения любого образовательного проекта - разработка и упаковка позиционирования проекта. Позиционирование - это то уникальное, отличительное место в нише, которое центр занимает среди прочих логопедических и реабилитационных центров своего города.

Мы построили позиционирование моего клиента на трех основных ценностях, близких основателю центра, команде специалистов и семьям, которые обращаются к ним за помощью:

1. Полное принятие детей с особенностями в развитии.

2. Желание адаптировать ребенка для жизни в обществе максимально возможным образом.

3. Оказание реабилитационных услуг высочайшего качества, в том 


\section{МОДЕРНИЗАЦИЯ СОВРЕМЕННОГО ОБРАЗОВАНИЯ: АНАЛИЗ ОПЫТА И ТЕНДЕНЦИЙ}

числе, с помощью привлечения столичных специалистов для супервизии.

Следующим шагом разработки стратегии стал глубокий анализ целевой аудитории проекта. Мы провели customer development (глубинные интервью с клиентами и потенциальными потребителями услуг центра) и досконально изучили:

- Кто эти семьи, которые обращаются за помощью в центр.

- Какое у них отношение к диагнозу ребенка.

- Каковы их ожидания от сотрудничества с центром реабилитации.

- Какие страхи и сомнения сопровождают для них выбор реабилитационного центра.

- Какую часть своего семейного дохода они готовы потратить на решение проблемы.

- Насколько быстро они готовы решать свою проблему.

- Какими альтернативными решениями они могут воспользоваться и где ищут информацию.

- Какие критерии для них важны при выборе центра развития речи, а чем они могут пожертвовать.

Ответы на эти вопросы мы получали с помощью таких инструментов, как проведение глубинных интервью и анкетирование клиентов реабилитационного центра, изучение спроса в нише и анализ конкурентов.

Мы также выделили критерии отстройки реабилитационного центра от других подобных центров города. Ими стали:

1. Наличие аппаратных средств реабилитации в центре (биоакустическая коррекция (БАК), Томатис-терапия), на которые был выявлен спрос в ходе анализа целевой аудитории.

2. Разработка системы работы с родителями и семьями особенных детей: ведение дневника наблюдений, рабочая тетрадь для родителей, обучающие семинары для родителей, адаптация других детей в семье к жизни с особенным братом или сестрой и др.

3. Найм в штат реабилитационного центра врача-невролога и расширение спектра оказываемых медицинских услуг.

4. Внедрение в проект современных образовательных трендов (с адаптацией под специфику работы с особенными детьми): геймификации, микрообучения, визуализации образовательной траектории, иммерсионного опыта в обучении. 


\section{МОДЕРНИЗАЦИЯ СОВРЕМЕННОГО ОБРАЗОВАНИЯ: АНАЛИЗ ОПЫТА И ТЕНДЕНЦИЙ}

5. Создание широкой продуктовой линейки под разные запросы и возможности целевой аудитории, а также под разные возрастные группы детей от 2 до 18 лет.

Все это вкупе позволило разработать уникальное позиционирование реабилитационного центра и приступить к следующему шагу - построению работающей финансовой модели центра.

Мы начали с расчета нового ценообразования, в котором подняли цены на продукты и оптимизировали существующие расходы, добившись рентабельности проекта в 20\% (при исходной рентабельности $0 \%$ ). Важным пунктом стало назначение основателю центра заработной платы за выполняемые ею обязанности и выделение финансовых средств на нового сотрудника в штате - администратора.

В итоге мы помесячно просчитали необходимое количество учеников центра и число оказываемых услуг для выхода на положительную прибыль не менее 200 тыс. руб. ежемесячно.

Следующий шаг построения стратегии развития - это выстраивание маркетинговой стратегии привлечения необходимого количества учеников в центр. Нами были проделаны следующие шаги:

1. Рассчитана предельно допустимая стоимость привлечения одного нового ученика и выделен необходимый маркетинговый бюджет.

2. Выбраны каналы продвижения, оптимальные именно для этого реабилитационного центра в конкретном городе.

3. Составлены офферы (ценностные предложения) и воронки продаж для каждого канала продвижения.

4. Создан сайт реабилитационного центра и упакованы социальные сети.

5. Настроена система аналитики с целью измерения результатов продвижения в каждом из выбранных каналов.

6. Необходимые шаги прописаны в виде подробного маркетинг-плана.

7. Доработана система продаж услуг центра, в том числе:

- составлена книга работы с возражениями,

- описаны и внедрены регламенты продаж,

- разработана линейка дополнительных продуктов для повышения прибыли,

- разработана система лояльности для постоянных клиентов, 


\section{МОДЕРНИЗАЦИЯ СОВРЕМЕННОГО ОБРАЗОВАНИЯ: АНАЛИЗ ОПЫТА И ТЕНДЕНЦИЙ}

- внедрены акции для социально незащищенных семей,

- нанят сотрудник, который будет заниматься продажами услуг, для него разработана система контроля и мотивации,

- $\quad$ внедрен план работы с текущими учениками центра для повышения их лояльности.

8. Маркетинг-план и система продаж реализованы руководителем центра за 2 месяца, в результате чего полностью проданы места на летние интенсивы и набрано запланированное количество учеников на новый учебный сезон 2021-22.

Последним шагом работы над стратегией проекта было создание системы управления, которая позволила бы основателю центра полностью выйти из операционной деятельности и сосредоточиться на стратегическом управлении проектом.

Какие шаги мы для этого предприняли:

- Выделили задачи проекта, которые до сих пор не выполнялись ввиду отсутствия сотрудников или ложились на плечи руководителя.

- Под эти задачи составили вакансии и провели найм нужных специалистов.

- Для всех сотрудников центра разработали систему мотивации, пересмотрели уровень оплат (для кого-то в большую, для других в меньшую сторону).

- Выделили главные функции руководителя и объективно оценили, насколько сейчас руководитель занимается именно этими функциями.

- Составили план развития управленческих компетенций руководителя.

- Внедрили в работу центра необходимые регламенты и автоматизировали часть процессов.

- Обозначили возможные векторы развития проекта на 1 год и 3 года вперед. Описали основные цели и шаги по их достижению.

() Ю.П. Федорова, 2021 